\title{
SYNTHESIS, IMMUNOSUPPRESSIVE PROPERTIES, MECHANISM OF ACTION AND X-RAY ANALYSIS OF A NEW CLASS OF ISOXAZOLE DERIVATIVES
}

\author{
URSZULA BĄCHOR ${ }^{1}$, STANISŁAW RYNG' ${ }^{1}$, MARCIN MĄCZYŃSKI', \\ JOLANTA ARTYM², MAJA KOCIĘBA², EWA ZACZYŃSKA², \\ IWONA KOCHANOWSKA ${ }^{2}$, EWA TYKARSKA ${ }^{3}$ and MICHA€ ZIMECKI ${ }^{2}$
}

\author{
'Department of Organic Chemistry, Medical University, \\ Borowska 211A, 50-556 Wrocław, Poland \\ ${ }^{2}$ Institute of Immunology and Experimental Therapy, Polish Academy of Sciences, \\ Department of Experimental Therapy, R. Weigla 12, 53-114 Wrocław, Poland \\ ${ }^{3}$ Department of Chemical Technology of Drugs, Poznan University of Medical Sciences, \\ Grunwaldzka 6, 60-780 Poznań, Poland
}

\begin{abstract}
In the search for potential therapeutics, isoxazole derivatives are still objects of interest. Previously described immunoregulatory properties of 5-amino-3-methyl-4-isoxazolecarboxylic acid (AC) benzylamides prompted us to synthesize a new class of compounds of immunotropic activity. A series of new compounds containing the isoxazole moiety were synthesized using Passerini three-component reaction. The effects on phytohemagglutinin A (PHA)-induced proliferation of human peripheral blood mononuclear cells (PBMC), production of tumor necrosis factor alpha (TNF $\alpha$ ) in human whole blood cultures stimulated with lipopolysaccharide (LPS) and two-way mixed lymphocyte reaction (MLR) of PBMC, were investigated. Also, the effect of 1-(cyclohexylcarbamoyl)cyclohexyl 5-amino-3-methylisoxazole-4-carboxylate (PUB1) on the expression of signaling molecules associated with cell apoptosis in Jurkat cells was also determined. The results showed that the compounds inhibited to various degree mitogen-induced PBMC proliferation in a dose-dependent manner and TNF $\alpha$ production at $10 \mu \mathrm{g} / \mathrm{mL}$. PUB1 compound, selected on the basis of its strongest antiproliferative activity, was also shown to inhibit MLR. The molecular data suggest that immunosuppressive action of PUB1 depended on induction of Fas and elevation of caspase 8 expression. In summary, we revealed the immunosuppressive properties of a new class of isoxazoles and established the mechanism of action of a representative PUB1 compound.
\end{abstract}

Keywords: isoxazoles, Passerini three-component reaction, proliferation, apoptosis, Jurkat cells

Heterocyclic compounds play an important role in drug design. They are main elements of a wide range of natural products, such as nucleic acids, amino acids, alkaloids, and vitamins. The pharmacological benefits of employing isoxazole moiety are due to the fact that this structure acts as a key pharmacophore for the biological activity of such drugs as valdecoxib (COX-2 inhibitor) (1) or leflunomide (antirheumatic drug) (2). The compounds containing isoxazole moiety are also promising therapeutic agents in neurodegenerative diseases due to their similarity to the $\alpha$-amino- 3 hydroxy-5-methyl-4-isoxazolepropionic acid, that is a specific agonist for the AMPA receptor (3). Based on the structure of these drugs, the series of com- pounds containing the isoxazole moiety were synthesized by Ryng et al. and their immunological profiles were examined (4-7). Of interest, among all compounds synthesized by our team, the modification in position 4 of the isoxazole structure led to unexpected biological activity. Our previous studies describing the synthesis of N-phenyl-5-amino-3methylisoxazole-4-carboxamides, containing different substituents in the phenyl ring, revealed the structure-activity relationship in some immunological tests (8). These results prompted us to continue the search for new derivatives of 4-substituted isoxazoles. The syntheses resulted in obtaining a series of amides as well as 4-ureilene derivatives of 5amino-3-methyl-4-isoxazolecarboxylic acid exhibit-

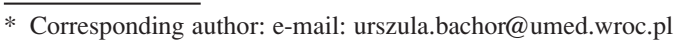


ing immunosuppressive or immunostimulating effects on the lipopolysaccharide (LPS)-induced production of tumor necrosis factor alpha (TNF $\alpha$ ) and interleukin-6 (IL-6) by human peripheral blood cells (9-12). 5-amino-3-methylisoxazole-4-carbonyl azide undergoes a Curtius rearrangement to form a 4-ureilene isoxazole derivative in the reaction with weak bases. The examples of different approaches of modifications of the substituents in position 4 of the isoxazole moiety are presented in Figure 1. In the course of further research on active immunomodulators, 5-amino-3-methyl-4-isoxazolecarboxylic acid semicarbazides and thiosemicarbazides were synthesized (13). Next, we obtained and examined the series of selected 5-amino-3-methyl-4-isoxazolecarboxylic acid benzylamides because of their immunological activities using several tests in vitro and in vivo, in mouse and human models. The screening of these compounds revealed potential therapeutic value of 5-amino-3-methyl-N-(4-methylbenzyl)-4-isoxazolecarboxamide (MO5). The compound exhibited strong anti-proliferative and anti-inflammatory properties. On the other hand, MO5 had the ability to enhance manifestation of the cellular immune response (14).

The obtained results showed that many of the compounds exhibited immunosuppressive effects on phytohemagglutinin (PHA)-induced PBMC proliferation. Additionally, several biological studies showed that the isoxazole structure was responsible for immunological activity (15).

To continue modifications of the position 4 of the isoxazole moiety and to expand the diversity of the synthesized compounds, we decided to employ Passerini three-component reaction. It is one of the most known types of multicomponent reactions (MCRs) and is a very useful synthetic tool in the search for new structures of potential immunological activity $(16,17)$. This type of procedure is crucial in drug design due to the simplicity of one-pot synthesis and provides a maximum of the diversity of possible structures. More than two starting materials are used to obtain the final product composed of the atoms of the substrates. A simple one-pot onestep procedure instead of multiple sequential steps make multicomponent reactions a valuable tool in combinatorial chemistry by giving the opportunity to obtain a large number of compounds in a short time. The Passerini three-component reaction provides an efficient way to obtain a-acyloxycarboxamides from carboxylic acid, carbonyl compound (aldehyde, ketone) and isocyanide (18). Thus, we could anticipate that the application of the isoxazole moiety in the multicomponent reactions increases the possibility of formation of compounds presenting potential biological activity.

The present study aimed to synthesize new derivatives of 5-amino-3-methylisoxazole-4-carboxylic acid (AC) using Passerini multicomponent reaction, evaluate the activity of the compounds in selected immunological models in vitro and to establish a mechanism of action of one representative compound from this series.

\section{EXPERIMENTAL}

\section{Materials and methods}

\section{Chemistry}

Melting points were determined on Büchi apparatus (Laboratoriums-Technik AG, Flawil, Switzerland), heated table Kofler system (Wagner \& Munz). Thin layer chromatography (TLC) was carried out on Polygram SIl G/UV 254 nm glass silica gel plates (Macherey-Nagel), using the developing system $\mathrm{CHCl}_{3}-$ EtOAc $3: 7$, and detected with UV Krüss Optronic $254 \mathrm{~nm}$ lamp. Complete ${ }^{1} \mathrm{H}$ NMR and ${ }^{13} \mathrm{C}$ NMR were performed for samples dissolved in $\mathrm{DMSO}-\mathrm{d}_{6}$ or $\mathrm{CDCl}_{3}$. NMR spectra were recorded in high-field spectrometer Bruker Avance $500 \mathrm{MHz}$ using TMS as the internal standard. Mass spectrometry was performed on Bruker Daltonic ESI-Q-TOF apparatus. The new products were analyzed using a Vario EL III CHNS, Elementar (Germany).

General procedure for the synthesis of PUB series

$5.6 \mathrm{mmol}$ of 5-amino-3-methylisoxazole-4carboxylic acid (AC) and appropriate aldehyde or ketone $(5.6 \mathrm{mmol})$ were dissolved in $15 \mathrm{~mL}$ of methanol under boiling. The reaction mixture was heated with stirring at reflux for a half an hour. Then the solution was cooled to the room temperature and a proper isocyanide was added $(5.6 \mathrm{mmol})$. The reaction mixture was heated under reflux for $72 \mathrm{~h}$ or $96 \mathrm{~h}$. Then the suspension was cooled and filtered. The crude product was recrystallized from methanol or THF.

5-amino-3-methylisoxazole-4-carboxylic acid (AC) Obtained as white powder, mp $168-169^{\circ} \mathrm{C},{ }^{1} \mathrm{H}$ NMR (500 MHz, DMSO-d $\left.{ }_{6}\right) \delta$ ppm: 2.17 (s, 3H, $\left.\mathrm{CH}_{3}\right), 7.57\left(\mathrm{~s}, 2 \mathrm{H}, \mathrm{NH}_{2}\right), 12.16(\mathrm{~s}, 1 \mathrm{H}, \mathrm{COOH}) .{ }^{13} \mathrm{C}$ NMR (126 MHz, DMSO-d $\left.{ }_{6}\right) \delta$ ppm: $171.71,164.31$, 159.33, 85.03, 11.62. MS $\left(\mathrm{ESI}^{+}\right)$Calc. for $\mathrm{C}_{5} \mathrm{H}_{7} \mathrm{~N}_{2} \mathrm{O}_{3}(\mathrm{M}+\mathrm{H})^{+}$143.0451; found 143.0467; calc. $(\mathrm{M}+\mathrm{Na})^{+}$165.0271; found 165.0286. Analysis: calcd. for $\mathrm{C}_{5} \mathrm{H}_{7} \mathrm{~N}_{2} \mathrm{O}_{3}$ : C, 42.26; $\mathrm{H}, 4.26 ; \mathrm{N}, 19.71 \%$; found: C, 42.18; H, 4.18; N, 19.68\%. 
1-(cyclohexylcarbamoyl)cyclohexyl 5-amino-3methylisoxazole-4-carboxylate (PUB1)

Obtained as white powder, yield $29.57 \%$, mp 205-206 ${ }^{\circ} \mathrm{C},{ }^{1} \mathrm{H}$ NMR $\left(500 \mathrm{MHz}, \mathrm{CDCl}_{3}\right) \delta \mathrm{ppm}$ : $1.07-1.15,1.25-1.38,1.49-1.71(\mathrm{~m}, 18 \mathrm{H}$, cyclohexyl), 1.61 (s, 3H, $\left.\mathrm{CH}_{3}\right), 2.24(\mathrm{~d}, J=14.0 \mathrm{~Hz}, 2 \mathrm{H}$, cyclohexyl), 3.73-3.81 (m, 1H, CH), 5.52 (d, $J=8.2$ $\mathrm{Hz}, 1 \mathrm{H}, \mathrm{NH}), 6.15$ (s, 2H, $\left.\mathrm{NH}_{2}\right) .{ }^{13} \mathrm{C} \mathrm{NMR}(126$ $\left.\mathrm{MHz}, \mathrm{CDCl}_{3}\right) \delta$ ppm: $172.28(\mathrm{C}, \mathrm{C}-5), 172.24(\mathrm{C}=\mathrm{O}$, $\mathrm{C}-17), 162.56$ (C, C-3), 159.28 (C=O, C-7), 87.01 (C, C-4), 82.58 (C, C-9), 48.12 (CH, C-20), 33.04 $\left(\mathrm{CH}_{2}, \mathrm{C}-21, \mathrm{C}-25\right), 32.77\left(\mathrm{CH}_{2}, \mathrm{C}-10, \mathrm{C}-14\right), 25.65$ $\left(\mathrm{CH}_{2}, \mathrm{C}-23\right), 25.23\left(\mathrm{CH}_{2}, \mathrm{C}-12\right), 24.88\left(\mathrm{CH}_{2}, \mathrm{C}-22\right.$, C-24), $21.80\left(\mathrm{CH}_{2}, \mathrm{C}-11, \mathrm{C}-13\right), 12.62\left(\mathrm{CH}_{3}, \mathrm{C}-6\right)$. MS (ESI ${ }^{+}$) Calc. for $\mathrm{C}_{18} \mathrm{H}_{27} \mathrm{~N}_{3} \mathrm{O}_{4}(\mathrm{M}+\mathrm{H})^{+} 350.2074$; found 350.2096; calc. $(\mathrm{M}+\mathrm{Na})^{+} 372.1894$; found 372.1908; calc. $(\mathrm{M}+\mathrm{K})^{+} 388.1633$; found 388.1643. Analysis: calcd. for $\mathrm{C}_{18} \mathrm{H}_{27} \mathrm{~N}_{3} \mathrm{O}_{4}$ : C, 61.87; H, 7.79; $\mathrm{N}, 12.03 \%$; found: C, 61.95; H, 7.84; N, $12.03 \%$.

(cyclohexylcarbamoyl)(4-methoxyphenyl)methyl 5-amino-3-methylisoxazole-4-carboxylate (PUB2)

Obtained as white powder, yield $22.82 \%, \mathrm{mp}$ $224-225^{\circ} \mathrm{C},{ }^{1} \mathrm{H}$ NMR $\left(500 \mathrm{MHz}, \mathrm{DMSO}-\mathrm{d}_{6}\right) \delta \mathrm{ppm}$ : 1.0-1.75 (m, 10H, cyclohexyl), $3.31\left(\mathrm{~s}, 3 \mathrm{H}, \mathrm{CH}_{3}\right)$, 3.46-3.51 (m, 1H, NCH, cyclohexyl), 3.75 (s, 3H, $\left.\mathrm{CH}_{3}\right), 5.94(\mathrm{~s}, 1 \mathrm{H}, \mathrm{CH}), 6.93-6.95(\mathrm{~m}, 2 \mathrm{H}$, aromatic protons), 7.40-7.43 (m, 2H, aromatic protons), 7.80 $\left(\mathrm{s}, 2 \mathrm{H}, \mathrm{NH}_{2}\right), 8.05$ (d, $\left.J=7.8 \mathrm{~Hz}, 1 \mathrm{H}, \mathrm{NH}\right) .{ }^{13} \mathrm{C} \mathrm{NMR}$ (126 MHz, DMSO-d ${ }_{6}$ $\delta$ ppm: $171.92(\mathrm{C}, \mathrm{C}-5)$, $167.41(\mathrm{C}=\mathrm{O}, \mathrm{C}-10), 161.44(\mathrm{C}, \mathrm{C}-3), 159.28(\mathrm{C}=\mathrm{O}$, C-7), 158.97 (C, C-17), 128.57 (C, C-14), 128.49 (CH, C-15, C-19), 113.78 (CH, C-16, C-18), 84.52 (C, C-4), 73.73 (CH, C-9), $55.09\left(\mathrm{CH}_{3}, \mathrm{C}-28\right), 47.64$ (CH, C-21), $32.05\left(\mathrm{CH}_{2}, \mathrm{C}-22, \mathrm{C}-26\right), 25.11\left(\mathrm{CH}_{2}\right.$, $\mathrm{C}-24), 24.46\left(\mathrm{CH}_{2}, \mathrm{C}-23, \mathrm{C}-25\right), 11.74\left(\mathrm{CH}_{3}, \mathrm{C}-6\right)$. MS $\left(\mathrm{ESI}^{+}\right)$Calc. for $\mathrm{C}_{20} \mathrm{H}_{25} \mathrm{~N}_{3} \mathrm{O}_{5}(\mathrm{M}+\mathrm{K})^{+} 426.1426$; found 426.1443. Analysis: calcd. for $\mathrm{C}_{20} \mathrm{H}_{25} \mathrm{~N}_{3} \mathrm{O}_{5}: \mathrm{C}$, 62.00; H, 6.50; N, 10.85\%; found: C, 61.94; H, 6.46; $\mathrm{N}, 10.81 \%$.

(cyclohexylcarbamoyl)(4-nitrophenyl)methyl 5amino-3-methylisoxazole-4-carboxylate (PUB3)

Obtained as yellowish powder, yield $34.03 \%$, mp $238-239^{\circ} \mathrm{C},{ }^{1} \mathrm{H}$ NMR (500 MHz, DMSO-d 6 ) $\delta$ ppm: 1.05-1.76 (m, 10H, cyclohexyl), 2.24 (s, 3H, $\mathrm{CH}_{3}$ ), 3.46-3.52 (m, 1H, NCH, cyclohexyl), 6.15 (s, $1 \mathrm{H}, \mathrm{CH}), 7.78-7.80(\mathrm{~m}, 2 \mathrm{H}$, aromatic protons), 7.87 (s, $2 \mathrm{H}, \mathrm{NH}_{2}$ ), 8.25-8.28 (m, $2 \mathrm{H}$, aromatic protons), $8.30(\mathrm{~d}, J=7.8 \mathrm{~Hz}, 1 \mathrm{H}, \mathrm{NH}) .{ }^{13} \mathrm{C} \mathrm{NMR}(126 \mathrm{MHz}$, DMSO-d $\left.{ }_{6}\right) \delta$ ppm: $172.08(\mathrm{C}, \mathrm{C}-5), 166.13(\mathrm{C}=\mathrm{O}$, C-10), 161.16 (C, C-3), 158.93 (C=O, C-7), 147.41 (C, C-14), 143.69 (C, C-17), 128.16 (CH, C-15, C19), 123.63 (CH, C-16, C-18), 84.25 (C, C-4), 73.30
(CH, C-9), 47.82 (CH, C-21), $32.10\left(\mathrm{CH}_{2}, \mathrm{C}-22, \mathrm{C}-\right.$ 26), 25.07( $\left.\mathrm{CH}_{2}, \mathrm{C}-24\right), 24.38\left(\mathrm{CH}_{2}, \mathrm{C}-23, \mathrm{C}-25\right)$, $11.88\left(\mathrm{CH}_{3}, \mathrm{C}-6\right)$. MS (ESI $\left.{ }^{+}\right)$Calc. for $\mathrm{C}_{19} \mathrm{H}_{22} \mathrm{~N}_{4} \mathrm{O}_{6}$ $(\mathrm{M}+\mathrm{H})^{+} 403.1612$; found 403.1623 ; calc. $(\mathrm{M}+\mathrm{Na})^{+}$ 425.1432; found 425.1449; calc. $(\mathrm{M}+\mathrm{K})^{+} 441.1171$; found 441.1178. Analysis: calcd. for $\mathrm{C}_{19} \mathrm{H}_{22} \mathrm{~N}_{4} \mathrm{O}_{6}$ : C, 56.71; H, 5.51; N, 13.92\%; found: C, 56.86; H, 5.54; $\mathrm{N}, 13.61 \%$.

(cyclohexylcarbamoyl)(pyridine-4-yl)methyl 5amino-3-methylisoxazole-4-carboxylate (PUB4)

Obtained as white powder, yield $8.37 \%$, mp 204$205^{\circ} \mathrm{C},{ }^{1} \mathrm{H}$ NMR $\left(500 \mathrm{MHz}, \mathrm{DMSO}-\mathrm{d}_{6}\right) \delta \mathrm{ppm}: 1.09-$ $1.58\left(\mathrm{~m}, 10 \mathrm{H}\right.$, cyclohexyl), $2.25\left(\mathrm{~s}, 3 \mathrm{H}, \mathrm{CH}_{3}\right), 3.48-$ 3.51 (m, 1H, NCH, cyclohexyl), 6.04 (s, 1H, CH), 7.48-7.49 (m, 2H, aromatic protons), $7.87(\mathrm{~s}, 2 \mathrm{H}$, $\left.\mathrm{NH}_{2}\right), 8.28(\mathrm{~d}, J=7.8 \mathrm{~Hz}, 1 \mathrm{H}, \mathrm{NH}), 8.59-8.60(\mathrm{~m}, 2 \mathrm{H}$, aromatic protons). ${ }^{13} \mathrm{C}$ NMR (126 MHz, DMSO-d 6 ) $\delta$ ppm: 172.07 (C, C-5), 166.01 (C=O, C-10), 161.19 (C, C-3), 158.93 (C=O, C-7), 149.79 (CH, C-16, C-18), 144.99 (C, C-14), 121.47 (CH, C-15, C-19), 84.25 (C, C-4), 72.96 (CH, C-9), 47.78 (CH, C-21), $32.08\left(\mathrm{CH}_{2}, \mathrm{C}-22, \mathrm{C}-26\right), 25.07\left(\mathrm{CH}_{2}, \mathrm{C}-24\right), 24.26$ $\left(\mathrm{CH}_{2}, \mathrm{C}-23, \mathrm{C}-25\right), 11.90\left(\mathrm{CH}_{3}, \mathrm{C}-6\right) . \mathrm{MS}\left(\mathrm{ESI}^{+}\right)$ Calc. for $\mathrm{C}_{18} \mathrm{H}_{22} \mathrm{~N}_{4} \mathrm{O}_{4}(\mathrm{M}+\mathrm{H})^{+}$359.1714; found 359.1746; calc. $(\mathrm{M}+\mathrm{Na})^{+} 381.1533$; found 381.1560 . Analysis: calcd. for $\mathrm{C}_{18} \mathrm{H}_{22} \mathrm{~N}_{4} \mathrm{O}_{4}: \mathrm{C}, 60.32 ; \mathrm{H}, 6.19 ; \mathrm{N}$, $15.63 \%$; found: C, $60.67 ; \mathrm{H}, 6.23 ; \mathrm{N}, 15.43 \%$.

(cyclohexylcarbamoyl)(phenyl)methyl 5-amino3-methylisoxazole-4-carboxylate (PUB5)

Obtained as white powder, yield $27.75 \%$, mp $224-225^{\circ} \mathrm{C},{ }^{1} \mathrm{H}$ NMR $\left(500 \mathrm{MHz}, \mathrm{DMSO}-\mathrm{d}_{6}\right) \delta \mathrm{ppm}$ : 1.05-1.75 (m, 10H, cyclohexyl), $2.22\left(\mathrm{~s}, 3 \mathrm{H}, \mathrm{CH}_{3}\right)$, 3.48-3.50 (m, 1H, NCH, cyclohexyl), $6.01(\mathrm{~s}, 1 \mathrm{H}$, $\mathrm{CH}), 7.32-7.40$ (m, 3H, aromatic protons), 7.50-7.51 (m, $2 \mathrm{H}$, aromatic protons), $7.83\left(\mathrm{~s}, 2 \mathrm{H}, \mathrm{NH}_{2}\right), 8.13$ $(\mathrm{d}, J=7.8 \mathrm{~Hz}, 1 \mathrm{H}, \mathrm{NH}) .{ }^{13} \mathrm{C}$ NMR $(126 \mathrm{MHz}$, DMSO-d $\left.{ }_{6}\right) \delta$ ppm: $171.96(\mathrm{C}, \mathrm{C}-5), 167.11(\mathrm{C}=\mathrm{O}$, C-10), 161.37 (C, C-3), 158.96 (C=O, C-7), 136.51 (C, C-14), 128.38 (CH, C-15, C-19), 128.33 (CH, C16, C-18), 126.99 (CH, C-17), 84.46 (C, C-4), 74.08 (CH, C-9), 47.67 (CH, C-21), $32.01\left(\mathrm{CH}_{2}, \mathrm{C}-22, \mathrm{C}-\right.$ 26), $25.10\left(\mathrm{CH}_{2}, \mathrm{C}-24\right), 24.32\left(\mathrm{CH}_{2}, \mathrm{C}-23, \mathrm{C}-25\right)$, $11.78\left(\mathrm{CH}_{3}, \mathrm{C}-6\right)$. MS (ESI $\left.{ }^{+}\right)$Calc. for $\mathrm{C}_{19} \mathrm{H}_{23} \mathrm{~N}_{3} \mathrm{O}_{4}$ $(\mathrm{M}+\mathrm{H})^{+} 358.1761$; found 358.1775 ; calc. $(\mathrm{M}+\mathrm{Na})^{+}$ 380.1581; found 380.1594. Analysis: calcd. for $\mathrm{C}_{19} \mathrm{H}_{23} \mathrm{~N}_{3} \mathrm{O}_{4}$ : C, 63.85; H, 6.49\%; N, 11.76; found: $\mathrm{C}$, 64.00; H, 6.36; N, $11.80 \%$.

(benzylcarbamoyl)(4-nitrophenyl)methyl 5-amino-3-methylisoxazole-4-carboxylate (PUB6)

Obtained as yellowish powder, yield $9.44 \%$, mp $228-229^{\circ} \mathrm{C},{ }^{1} \mathrm{H}$ NMR (500 MHz, DMSO-d $\left.{ }_{6}\right) \delta$ 
ppm: 2.26 (s, 3H, $\left.\mathrm{CH}_{3}\right), 4.28(\mathrm{~d}, J=10.5 \mathrm{~Hz}, 1 \mathrm{H}$, $\left.\mathrm{CH}_{2}\right), 6.24(\mathrm{~s}, 1 \mathrm{H}, \mathrm{CH}), 7.15(\mathrm{~d}, J=7.0 \mathrm{~Hz}, 2 \mathrm{H}$, aromatic protons), 7.19-7.24 (m, $1 \mathrm{H}$, aromatic proton), 7.28 (dd, $J=10.0 \mathrm{~Hz}, 2 \mathrm{H}$, aromatic protons), 7.83 (d, $J=8.8 \mathrm{~Hz}, 2 \mathrm{H}$, aromatic protons), 7.90 (s, 2H, $\mathrm{NH}_{2}$ ), 8.26-8.32 (m, 2H, aromatic protons), 8.94 (t, $J=5.9 \mathrm{~Hz}, 1 \mathrm{H}, \mathrm{NH}) \cdot{ }^{13} \mathrm{C} \mathrm{NMR}\left(126 \mathrm{MHz}, \mathrm{CDCl}_{3}\right) \delta$ ppm: 172.14 (C, C-5), 167.37 (C, C-3), 161.30 $(\mathrm{C}=\mathrm{O}, \mathrm{C}-10), 158.96(\mathrm{C}=\mathrm{O}, \mathrm{C}-7), 147.53(\mathrm{C}, \mathrm{C}-14)$, 143.27 (C, C-17), 138.68 (C, C-23), 128.36 (CH, C15, C-19), 128.28 (CH, C-25, C-26), 126.99 (CH, C24, C-27), 126.87 (CH, C-28), 123.69 (CH, C-16, C18), 84.23 (C, C-4), $73.65\left(\mathrm{CH}_{2}, \mathrm{C}-9\right), 42.08\left(\mathrm{CH}_{2}\right.$, $\mathrm{C}-22), 11.98\left(\mathrm{CH}_{3}, \mathrm{C}-6\right)$. MS $\left(\mathrm{ESI}^{+}\right)$Calc. for $\mathrm{C}_{20} \mathrm{H}_{18} \mathrm{~N}_{4} \mathrm{O}_{6}(\mathrm{M}+\mathrm{H})^{+}$411.1299; found 411.1314; $(\mathrm{M}+\mathrm{Na})^{+}$433.1119; found 433.1140. Analysis: calcd. for $\mathrm{C}_{20} \mathrm{H}_{18} \mathrm{~N}_{4} \mathrm{O}_{6}: \mathrm{C}, 58.53 ; \mathrm{H}, 4.42 ; \mathrm{N}, 13.65$; found: C, 58.63; H, 4.32; N, 13.78 .

(pentylcarbamoyl)(4-methoxyphenyl)methyl 5amino-3-methylisoxazole-4-carboxylate (PUB7)

Obtained as white powder, yield $3.21 \%$, mp $180-181^{\circ} \mathrm{C},{ }^{1} \mathrm{H}$ NMR $\left(500 \mathrm{MHz}, \mathrm{DMSO}-\mathrm{d}_{6}\right) \delta \mathrm{ppm}$ : $0.79\left(\mathrm{t}, J=7.2 \mathrm{~Hz}, 3 \mathrm{H}, \mathrm{CH}_{3}\right), 1.16-1.08(\mathrm{~m}, 2 \mathrm{H}$, $\left.\mathrm{CH}_{2}\right), 1.16-1.25\left(\mathrm{~m}, 2 \mathrm{H}, \mathrm{CH}_{2}\right), 1.30-1.38(\mathrm{~m}, 2 \mathrm{H}$, $\left.\mathrm{CH}_{2}\right), 2.21$ (s, $\left.3 \mathrm{H}, \mathrm{CH}_{3}\right), 2.95-3.09\left(\mathrm{~m}, 2 \mathrm{H}, \mathrm{CH}_{2}\right)$, 3.75 (s, 3H, $\left.\mathrm{CH}_{3}\right), 5.91$ (s, $\left.1 \mathrm{H}, \mathrm{CH}\right), 6.90-6.98$ (m, $2 \mathrm{H}$, aromatic protons $), 7.37-7.46(\mathrm{~m}, 2 \mathrm{H}$, aromatic protons), 7.80 (s, $\left.2 \mathrm{H}, \mathrm{NH}_{2}\right), 8.15(\mathrm{t}, J=5.7 \mathrm{~Hz}, 1 \mathrm{H}$, $\mathrm{NH}) .{ }^{13} \mathrm{C}$ NMR $\left(126 \mathrm{MHz}, \mathrm{CDCl}_{3}\right) \delta \mathrm{ppm}: 171.97$ (C, C-5), 168.27 (C, C-3), $161.50(\mathrm{C}=\mathrm{O}, \mathrm{C}-10)$, 159.35 (C=O, C-7), 158.98 (C, C-17), 128.60 (C, C14), 128.39 (CH, C-15, C-19), 113.80 (CH, C-16, C18), 84.49 (C, C-4), 74.02 (CH, C-9), $55.12\left(\mathrm{CH}_{3}\right.$, $\mathrm{C}-27), 38.35\left(\mathrm{CH}_{2}, \mathrm{C}-21\right), 28.53\left(\mathrm{CH}_{2}, \mathrm{C}-23\right), 28.36$ $\left(\mathrm{CH}_{2}, \mathrm{C}-22\right), 21.71\left(\mathrm{CH}_{2}, \mathrm{C}-24\right), 13.84\left(\mathrm{CH}_{3}, \mathrm{C}-25\right)$, $11.80\left(\mathrm{CH}_{3}, \mathrm{C}-6\right)$. MS (ESI $\left.{ }^{+}\right)$Calc. for $\mathrm{C}_{19} \mathrm{H}_{25} \mathrm{~N}_{3} \mathrm{O}_{5}$ $(\mathrm{M}+\mathrm{H})^{+} 376.1867$; found 376.1897 ; calc. $(\mathrm{M}+\mathrm{Na})^{+}$ 398.1686; found 398.1717. Analysis: calcd. for $\mathrm{C}_{19} \mathrm{H}_{25} \mathrm{~N}_{3} \mathrm{O}_{5}$ : C, 60.79; H, 6.71; N, 11.19\%; found: C, 61.06; H, 6.73; N, $11.33 \%$.

(cyclohexylcarbamoyl)(3-nitrophenyl)methyl 5amino-3-methylisoxazole-4-carboxylate (PUB8)

Obtained as yellowish powder, yield 29.70\%, mp $223-224^{\circ} \mathrm{C},{ }^{1} \mathrm{H}$ NMR $500 \mathrm{MHz}$, DMSO-d $\left.\mathrm{d}_{6}\right) \delta$ ppm: 0.99-1.32 (m, 5H, cyclohexyl), 1.42-1.82 (m, $5 \mathrm{H}$, cyclohexyl), 2.24 (s, 3H, $\left.\mathrm{CH}_{3}\right), 3.42-3.57$ (m, $1 \mathrm{H}, \mathrm{CH}), 6.16$ (s, 1H, CH), $7.72(\mathrm{t}, J=8.0 \mathrm{~Hz}, 1 \mathrm{H}$, aromatic proton), $7.88\left(\mathrm{~s}, 2 \mathrm{H}, \mathrm{NH}_{2}\right), 7.96(\mathrm{~d}, J=7.8$ $\mathrm{Hz}, 1 \mathrm{H}$, aromatic proton), 8.22 (ddd, $J=8.3 \mathrm{~Hz}, 2.4$ $\mathrm{Hz}, 1.0 \mathrm{~Hz}, 1 \mathrm{H}$, aromatic proton), $8.30(\mathrm{~d}, J=7.8$ $\mathrm{Hz}, 1 \mathrm{H}, \mathrm{NH}), 8.39$ (t, $J=2.0 \mathrm{~Hz}, 1 \mathrm{H}$, aromatic proton). ${ }^{13} \mathrm{C} \mathrm{NMR}\left(126 \mathrm{MHz}, \mathrm{CDCl}_{3}\right) \delta \mathrm{ppm}: 172.08(\mathrm{C}$,
C-5), 166.35 (C=O, C-10), 161.19 (C, C-3), 158.89 $(\mathrm{C}=\mathrm{O}, \mathrm{C}-7), 147.66$ (C, C-16), 138.57 (C, C-14), 133.47 (CH, C-19), 130.18 (CH, C-18), $123.34(\mathrm{CH}$, C-15), 121.75 (CH, C-17), 84.25 (C, C-4), 73.08 (C, $\mathrm{C}-9), 47.78(\mathrm{CH}, \mathrm{C}-21), 31.94\left(\mathrm{CH}_{2}, \mathrm{C}-22, \mathrm{C}-26\right)$, $25.06\left(\mathrm{CH}_{2}, \mathrm{C}-24\right), 24.25\left(\mathrm{CH}_{2}, \mathrm{C}-23, \mathrm{C}-25\right), 11.85$ $\left(\mathrm{CH}_{3}, \mathrm{C}-6\right)$. MS (ESI $\left.{ }^{+}\right)$Calc. for $\mathrm{C}_{19} \mathrm{H}_{22} \mathrm{~N}_{4} \mathrm{O}_{6}$ $(\mathrm{M}+\mathrm{H})^{+}$403.1612; found 403.1673; calc. $(\mathrm{M}+\mathrm{Na})^{+}$ 425.1432; found 425.1502. Analysis: calcd. for $\mathrm{C}_{19} \mathrm{H}_{22} \mathrm{~N}_{4} \mathrm{O}_{6}: \mathrm{C}, 56.71 ; \mathrm{H}, 5.51 ; \mathrm{N}, 13.92 \%$; found: $\mathrm{C}$, 56.87; H, 5.54; N, $13.80 \%$.

\section{Biological assays \\ Reagents}

HyClone $^{\circledast}$ Fetal bovine serum (FBS) was from Thermo Fisher Scientific (Waltham, USA). RPMI1640 and Hanks' medium was from Biowest SAS France and purchased from CytoGen GmbH (Sinn, Germany). ELISA kit from Thermo Fisher Scientific (Waltham, USA). Lipopolysaccharide (LPS) from Escherichia coli 0111:B4, phytohemagglutinin (PHA), dimethyl sulfoxide (DMSO) and MTT (3[4,5-dimethylthiazol-2-yl]-2,5-diphenyltetrazolium bromide) and all other reagents were from SigmaAldrich (St. Louis, USA).

\section{Preparation of the compounds for biological assays}

The compounds were dissolved in DMSO (10 $\mathrm{mg} / \mathrm{mL}$ ) and subsequently diluted in RPMI-1640 cell culture medium.

\section{Isolation of the peripheral blood mononuclear cells (PBMC)}

Venous blood from a single donor was withdrawn into heparinized syringes and diluted twice with PBS. PBMC were isolated by centrifugation on Ficoll-Uropoline gradient (density $1.077 \mathrm{~g} / \mathrm{mL}$ ) and the interphase cells were then washed three times with Hanks' medium and resuspended in a culture medium, referred to below as the culture medium, consisting of RPMI-1640, supplemented with $10 \%$ FCS, L-glutamine, sodium pyruvate, 2-mercaptoethanol, and antibiotics, at a density of $2 \times 10^{6}$ cells/mL.

\section{PHA-induced proliferation of human PBMC}

PBMC were distributed into 96-well flat bottom plates in $100 \mu \mathrm{L}$ aliquots $\left(2 \times 10^{5}\right.$ cells/well $)$. PHA was added at a concentration of $5 \mu \mathrm{g} / \mathrm{mL}$. The compounds were tested at doses of 100, 10 and $1 \mu \mathrm{g} / \mathrm{mL}$. DMSO at appropriate dilutions served as control. Leflunomide served as a reference drug. After 4-day incubation in a cell culture incubator, 
the proliferative response of the cells was determined by the colorimetric MTT method (19). The results, originally calculated as optical density (OD) values, were presented as percent inhibition in comparison to appropriate DMSO control (Table 1).

\section{Lipopolysaccharide-induced TNF a production in whole blood cell culture}

Human whole blood was diluted $10 \times$ with RPMI 1640 medium and distributed to 24-well culture plates in $1 \mathrm{~mL}$ aliquots. The cultures were stimulated with LPS (100 ng/mL) and the studied compounds were added at a studied concentration (10 $\mathrm{ng} / \mathrm{mL}$ ). The control cultures contained DMSO in an appropriate concentration. Leflunomide served as a reference drug. After an overnight or $4 \mathrm{~h}$ incubation, the supernatants were harvested and frozen at $-80^{\circ} \mathrm{C}$ until cytokine determination. TNF $\alpha$ levels were determined in the supernatants by using ELISA kit from Thermo Fisher Scientific, in the presence of TNF $\alpha$ standard, and originally expressed in $\mathrm{pg} / \mathrm{mL}$. The inhibition (in percentage) of TNF $\alpha$ production shown in Table 1 was calculated by comparison with appropriate DMSO controls.

\section{Colorimetric MTT assay for cell growth and kill}

The assay was performed according to (19). Briefly, $25 \mu \mathrm{L}$ of MTT $(5 \mathrm{mg} / \mathrm{mL})$ stock solution was added per well at the end of cell incubation period and the plates were incubated for additional $3 \mathrm{~h}$ in a cell culture incubator. Then, $100 \mu \mathrm{L}$ of the extraction buffer (20\% SDS with 50\% DMF, pH 4.7) was added. After overnight incubation, the OD

Table 1. The effects of PUB compounds on TNF $\alpha$ production. The cultures of human whole blood were stimulated with LPS $(100 \mathrm{ng} / \mathrm{mL})$ and the studied compounds (PUB1-PUB8) were added at a $10 \mu \mathrm{g} / \mathrm{mL}$ concentration. The control cultures contained DMSO in appropriate concentration. TNF $\alpha$ levels were determined in the supernatants by ELISA kit and originally expressed in $\mathrm{pg} / \mathrm{mL}$. The results are given in percentage inhibition as compared with appropriate DMSO controls.

\begin{tabular}{|c|c|}
\hline $\begin{array}{c}\text { Compound } \\
(10 \mu \mathrm{g} / \mathrm{mL})\end{array}$ & \% inhibition \\
\hline Leflunomide & 54 \\
\hline PUB1 & 10 \\
\hline PUB2 & 37 \\
\hline PUB3 & 30 \\
\hline PUB4 & 52 \\
\hline PUB5 & 27 \\
\hline PUB6 & 46 \\
\hline PUB7 & 34 \\
\hline PUB8 & 55 \\
\hline
\end{tabular}

was measured at $550 \mathrm{~nm}$ with the reference wavelength of $630 \mathrm{~nm}$ in a Dynatech 5000 spectrophotometer.

\section{Quantitation of gene expression by Real-Time PCR}

Total RNA isolation from Jurkat cells was carried with TRIzol Reagent (Ambion) accordingly to manufacturer's recommendations. The RNA pellet dried on air was dissolved in $20-30 \mathrm{~mL}$ of sterile diethylpyrocarbonate-treated Mili-Q water and stored at $-20^{\circ} \mathrm{C}$. Single-stranded complementary DNA (cDNA) was synthesized from $5 \mathrm{mg}$ of total RNA using Super verte Kit oligo (dT)15 (Novazym). The expression of genes for GAPDH, caspases $-3,-7,-8$ and $-9, \mathrm{Bcl}-2$, Fas, NF- $\kappa \mathrm{B} 1$ and p53 was determined with AmpliQ 5× HOT EvaGreen ${ }^{\circledast}$ qPCR Mix Plus (noROX) (Novazym).

\section{Mixed lymphocyte reaction (MLR)}

PBMC from two donors $\left(2 \times 10^{5}\right.$ cells/well each) in the culture medium were mixed and placed in flat bottom 96-well culture plates. The compounds were added to the cultures at a concentration of 50, 10 and $2 \mu \mathrm{g} / \mathrm{mL}$. The controls were represented by $2 \times 10^{5}$ cells/well of each blood donor. Appropriate DMSO controls were also prepared. Cyclosporine (CsA) served as a reference drug. After 5-day incubation in a cell culture incubator, the degree of cell proliferation was determined by MTT colorimetric method.

\section{Statistics}

The results are presented as mean values \pm standard error (SE). Brown-Forsyth's test was used to determine the homogeneity of variance between groups. When the variance was homogenous, analysis of variance (one-way ANOVA) was applied, followed by post hoc comparisons with the Tukey's test to estimate the significance of the difference between groups. Nonparametric data were evaluated with the Kruskal-Wallis' analysis of variance. Significance was determined at $\mathrm{p}<0.05$. Statistical analysis was performed using STATISTICA 7.0 for Windows.

\section{X-ray analysis}

Single crystals of PUB1 suitable for X-ray analysis were grown at room temperature by slow evaporation of chloroform solution. Summary of structure determination is given in Table 3. The diffraction intensity data were collected at $293 \mathrm{~K}$ using Oxford Diffraction SuperNova, Dual diffractometer with hi-flux microfocus Nova $\mathrm{Cu} \mathrm{K} \alpha$ radiation and processed with CrystAlisPro software (20). The 
structure was solved by direct methods with SHELXT (21) and refined by full matrix leastsquares based on $\mathrm{F}^{2}$ with SHELXL (22). All non-H atoms were refined anisotropically. The N-H hydrogen atoms were located in difference electron-density maps, and during refinement, the distances were fixed by AFIX 3 instruction. The C-bound hydrogen atoms were included in calculated positions. All Hatoms were refined as riding on their pivot atoms with $U_{\text {iso }}(\mathrm{H})=1.2 U_{\text {eq }}(\mathrm{C}, \mathrm{N})$ and $1.5 U_{\text {eq }}\left(\mathrm{CH}_{3}\right.$ groups).

Fractional atomic coordinates, anisotropic displacement parameters, the full list of bond lengths and angles in CIF format have been deposited at the Cambridge Crystallographic Data Centre with accession code CCDC 1496237.

\section{RESULTS AND DISCUSSION}

One of the most significant immunoactive compound with an isoxazole moiety is leflunomide which is used for the treatment of autoimmune disorders. In this work, we continue to search for the new isoxazole derivatives with potential biological activity. In our previous studies, we found that some unsubstituted and monosubstituted phenylamides of 5-amino-3-methylisoxazole-4-carboxylic acid (AC) are immunostimulators (11). However, some AC derivatives display suppressive effects on PHAinduced cell proliferation (23). Moreover, the studies between structure-activity relationships demonstrated that the immunostimulatory or immunosuppressive effects of isoxazole derivatives are correlat-

Table 2. The expression of signaling molecules in Jurkat cells after treatment with PUB1 following normalization against GADPH housekeeping gene. The table presents the absolute values calculated for each gene's expression as the difference between expression in a sample from PUB1 containing culture and that from a control one (DMSO). All values are rounded maximal to the third decimal place, and negative values are shown as zero.

\begin{tabular}{|c|c|c|c|c|c|c|c|c|}
\hline Gene & Casp-3 & Casp-7 & Casp-8 & Casp-9 & Bcl-2 & Fas & NF- B1 & p53 \\
\hline DMSO & 0.324 & 0.841 & 0.179 & 0.057 & 0.0 & 0.0 & 0.0 & 0.0 \\
\hline PUB1 & 0.475 & 0.320 & 0.540 & 0.0 & 0.0 & 1.0 & 0.0 & 0.0 \\
\hline
\end{tabular}

Table 3. X-ray experimental details for PUB1.

\begin{tabular}{|c|c|}
\hline & PUB1 \\
\hline Chemical formula & $\mathrm{C}_{18} \mathrm{H}_{27} \mathrm{~N}_{3} \mathrm{O}_{4}$ \\
\hline$M_{\mathrm{r}}$ & 349.42 \\
\hline $\begin{array}{l}\text { Crystal system, } \\
\text { space group }\end{array}$ & Monoclinic, $P 2_{1} / n$ \\
\hline$a, b, c(\AA)$ & $9.7331(1), 10.9221(1), 18.1951$ (2) \\
\hline $\mathrm{a}, \mathrm{b}, \mathrm{g}\left({ }^{\circ}\right)$ & $90,94.422(1), 90$ \\
\hline$V\left(\AA^{3}\right)$ & $1928.49(3)$ \\
\hline$Z$ & 4 \\
\hline $\mathrm{m}\left(\mathrm{mm}^{-1}\right)$ & 0.70 \\
\hline Crystal size (mm) & $0.35 \times 0.15 \times 0.15$ \\
\hline$T_{\min }, T_{\max }$ & $0.836,1.000$ \\
\hline $\begin{array}{l}\text { No. of measured, } \\
\text { independent and } \\
\text { observed }[I>2 \mathrm{~s}(I)] \\
\text { reflections }\end{array}$ & $19690,3659,3233$ \\
\hline$R_{\mathrm{int}}$ & 0.029 \\
\hline$(\sin q / 1)_{\max }\left(\AA^{-1}\right)$ & 0.610 \\
\hline $\begin{array}{c}R\left[F^{2}>2 \mathrm{~s}\left(F^{2}\right)\right] \\
\quad w R\left(F^{2}\right), S\end{array}$ & $0.037,0.104,1.04$ \\
\hline No. of reflections & 3659 \\
\hline No. of parameters & 228 \\
\hline $\mathrm{D} \tilde{\mathrm{n}}_{\max }, \mathrm{D} \tilde{\mathrm{n}}_{\min }\left(\mathrm{e} \AA^{-3}\right)$ & $0.20,-0.15$ \\
\hline
\end{tabular}




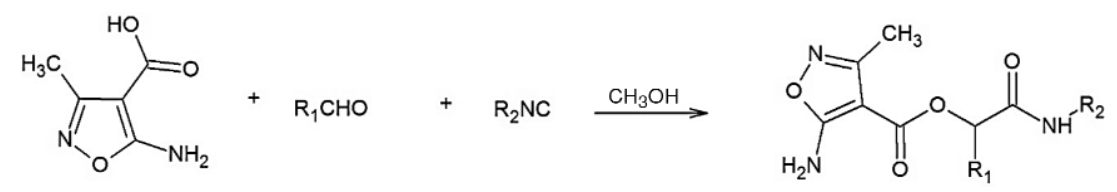

Scheme 1. Synthesis of 5-amino-3-methyl-4-isoxazolecarboxylic acid derivatives in Passerini three-component reaction (PUB series)

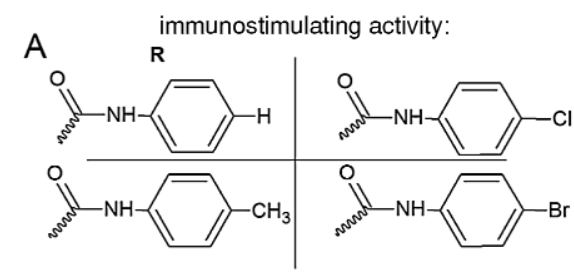

immunostimulating activity:<smiles>CCCCCCC(=O)Nc1cc(OC)c(OC)c(OC)c1</smiles>

B

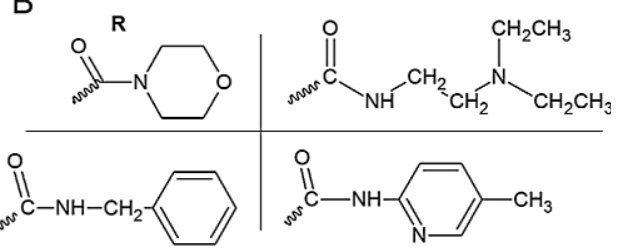

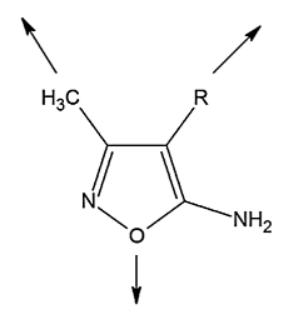

C

immunosuppressory activity:<smiles>[R]NC(=O)NC</smiles>

Figure 1. The diversity of structures of isoxazole derivatives and their different immunological activities (A: (11), B: (12), C: (10))

Table 4. Selected hydrogen-bond parameters for PUB1.

\begin{tabular}{|c|c|c|c|c|}
\hline$D-\mathrm{H} \cdots A$ & $D-\mathrm{H}(\AA)$ & $\mathrm{H} \cdots A(\AA)$ & $D \cdots A(\AA)$ & $D-\mathrm{H} \cdots A\left({ }^{\circ}\right)$ \\
\hline $\mathrm{N} 1-\mathrm{H} 1 \mathrm{~N} 1 \cdots \mathrm{O} 2$ & 0.90 & 2.30 & $2.880(1)$ & 122 \\
\hline $\mathrm{N} 1-\mathrm{H} 1 \mathrm{~N} 1 \cdots \mathrm{O} 2^{\mathrm{i}}$ & 0.90 & 2.15 & $2.942(1)$ & 147 \\
\hline $\mathrm{N} 1-\mathrm{H} 2 \mathrm{~N} 1 \cdots \mathrm{O} 4^{\mathrm{i}}$ & 0.89 & 2.20 & $2.945(2)$ & 141 \\
\hline $\mathrm{N} 3-\mathrm{H} 1 \mathrm{~N} 3 \cdots \mathrm{N} 2^{\mathrm{ii}}$ & 0.94 & 2.26 & $3.167(1)$ & 160 \\
\hline
\end{tabular}

Symmetry codes: (i) $+\mathrm{x}+2,+\mathrm{y}+1,+\mathrm{z}+1$; (ii) $+\mathrm{x}+1,+\mathrm{y}+1,+\mathrm{z}+1$

ed with a location of the substituents in the phenyl ring (12). The results prompted us to synthesize a series of new isoxazole derivatives and to investigate their immunological activities. The idea was to obtain a new class of compounds which consist of the basic structure of isoxazole and as well containing the amide bond which seems to be crucial for the biological activity. The proposed strategy allowed us to prepare the combinatorial library of isoxazole containing compounds, which were investigated for their potential inhibitory effects on LPS-induced TNF $\alpha$ production in the human whole blood cultures and as well as their ability to suppress PHAinduced proliferation of human PBMC. 


\section{Chemistry}

Our study was initiated by the preparation of 5amino-3-methylisoxazole-4-carboxylic acid by the method described by Klötzer et al. (24) and then the hydrolysis of the obtained ethyl 5-amino-3methylisoxazole-4-carboxylate intermediate (25). We decided to apply 5-amino-3-methylisoxazole-4carboxylic acid in the Passerini three-component reaction to provide a wide range of its new deriva- tives. The mixture of AC, carbonyl compound (aldehyde, ketone) and isocyanide was heated up to the boiling point of the used solvent and stirred under reflux (Scheme 1). The reaction product formed a precipitate which was filtered and purified by recrystallization from methanol or THF. The obtained compounds were analyzed by mass spectrometry and NMR spectroscopy. ${ }^{1} \mathrm{H}$ NMR spectrum of model compound PUB1 is shown in Figure 2.<smiles>[M]C1CCC(OC(=O)c2c(C)coc2N)(C(=O)NC2CCC([M])C2)CC1</smiles>

$\mathrm{CDCl}_{3}$

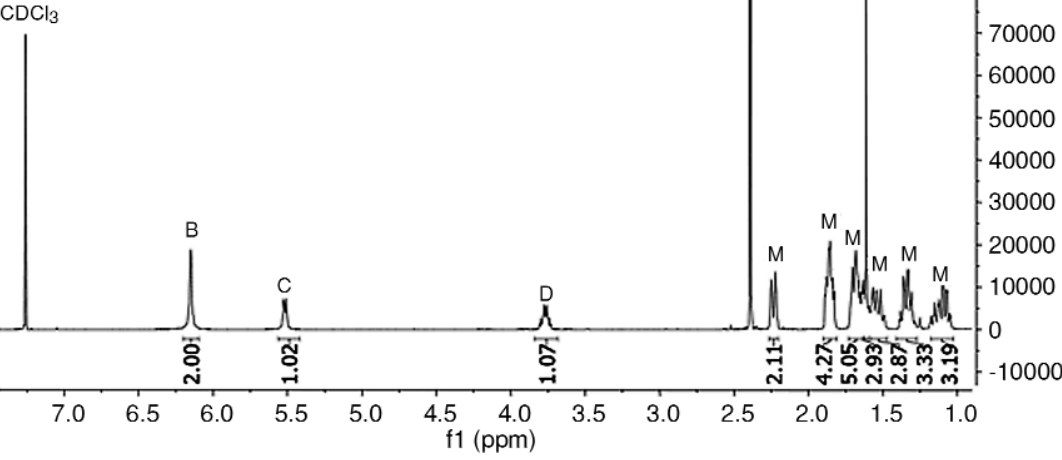

Figure 2. 'H NMR spectrum of model compound PUB1

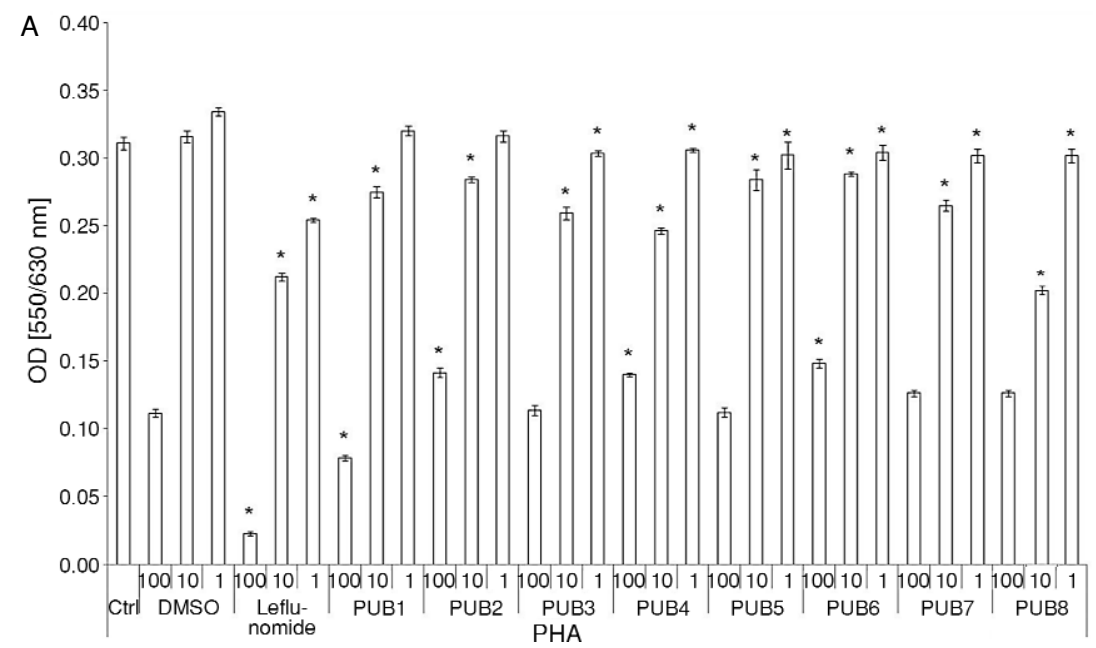

Figure 3A. The effect of PUB compounds (A) on PHA-induced human PBMC proliferation. PHA was added into human PBMC cultures at a concentration of $5 \mu \mathrm{g} / \mathrm{mL}$. The compounds were tested at doses of 100,10 and $1 \mu \mathrm{g} / \mathrm{mL}$ (PUB1-PUB8) and 100, 50, 25 and 12.5 $\mu \mathrm{g} / \mathrm{mL}$ (PUB1). DMSO at appropriate dilutions served as control. The proliferative response of the cells was determined by the colorimetric MTT method. The results, originally calculated as OD values, are presented as percent inhibition in comparison to appropriate DMSO control. Ctrl (Control) - only RPMI-1640 medium. Statistics: *, versus DMSO $(\mathrm{p}<0.05)$ 


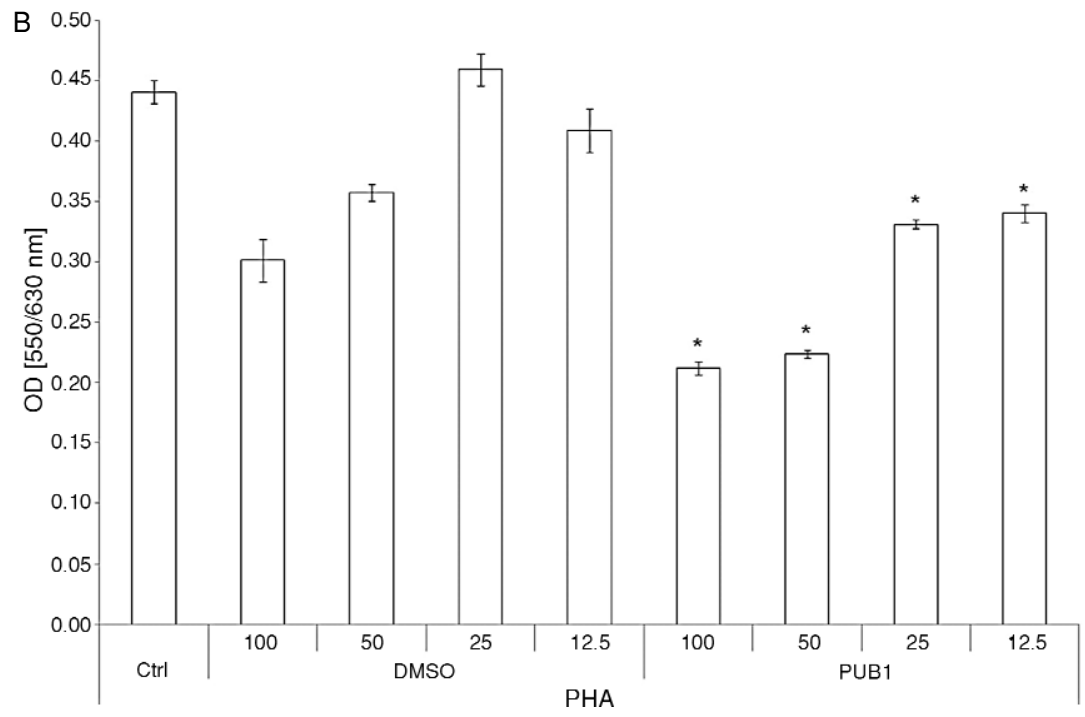

Figure 3B. The effect of PUB1 (B) on PHA-induced human PBMC proliferation. PHA was added into human PBMC cultures at a concentration of $5 \mu \mathrm{g} / \mathrm{mL}$. The compounds were tested at doses of 100, 10 and $1 \mu \mathrm{g} / \mathrm{mL}$ (PUB1-PUB8) and 100, 50, $25 \mathrm{and} 12.5 \mu \mathrm{g} / \mathrm{mL}$ (PUB1). DMSO at appropriate dilutions served as control. The proliferative response of the cells was determined by the colorimetric MTT method. The results, originally calculated as OD values, are presented as percent inhibition in comparison to appropriate DMSO control. Ctrl (Control) - only RPMI-1640 medium. Statistics: *, versus DMSO $(\mathrm{p}<0.05)$

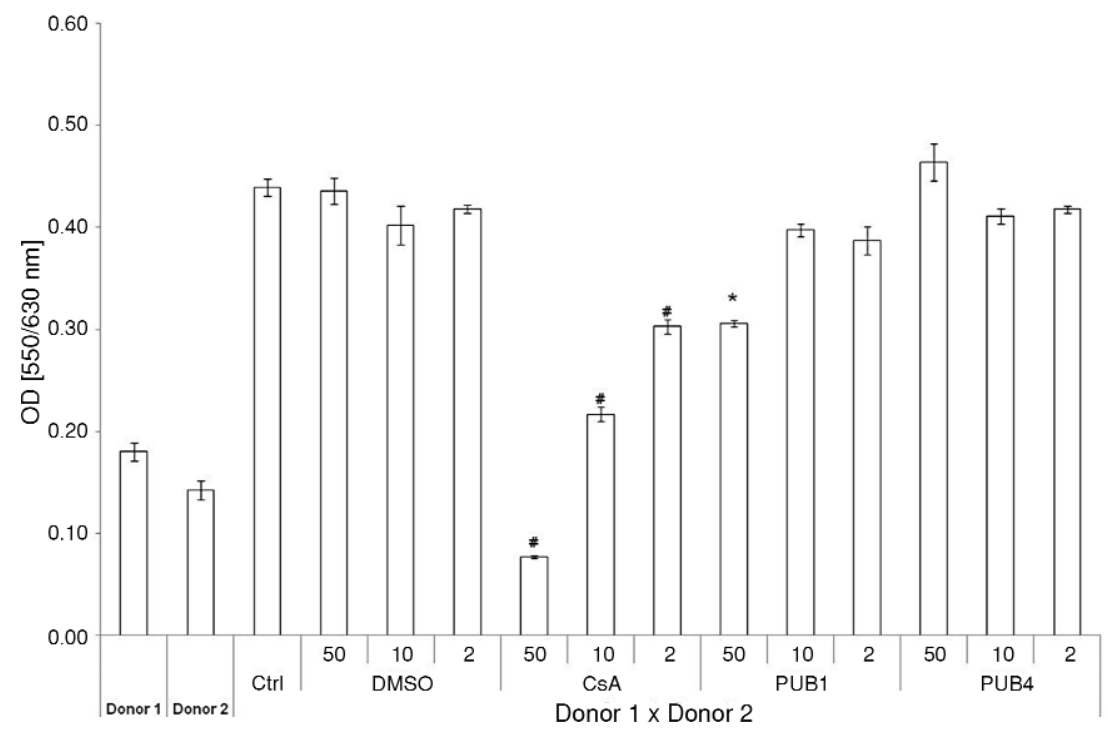

Figure 4. The effects of PUB1 and PUB4 compounds on two-way mixed lymphocyte reaction of human PBMC. PBMC from two donors were mixed and PUB1 or PUB4 were added to the cultures at a concentration of 50,10 and $2 \mathrm{erg} / \mathrm{mL}$. The controls were represented by cells of each blood donor. Appropriate DMSO controls were also prepared. The degree of cell proliferation was determined by MTT colorimetric method. The results, originally calculated as OD values, are presented as percent inhibition in comparison to appropriate DMSO control. Ctrl (Control) - only RPMI-1640 medium. Statistics: \#, versus Ctrl; *, versus DMSO (p <0.05)

\section{Biological evaluation}

The tests showed that the compounds inhibited in a differential, dose-dependent way PHA-induced proliferation of human PBMC (Fig. 3A) and TNF $\alpha$ production at $10 \mu \mathrm{g} / \mathrm{mL}$ (Table 1) in whole blood cell cultures. All compounds were non-toxic against A549 reference cell line (a human lung cancer cell line, ATCC CCL 185) at 10-100 $\mu \mathrm{g} / \mathrm{mL}$ concentration range (data are not shown). The most suppressive compound in the model of PHA-induced prolif- 
eration of PBMC was PUB1 (1-(cyclohexylcarbamoyl)cyclohexyl 5-amino-3-methylisoxazole-4carboxylate), based on its activity at $100 \mu \mathrm{g} / \mathrm{mL}$. This was confirmed in a further experiment (Fig. 3B) showing still its moderate suppressive activity at a concentration of 25 and $12.5 \mu \mathrm{g} / \mathrm{mL}$.
Nevertheless, the compound only slightly inhibited LPS-induced TNF $\alpha$ in whole blood cell cultures (Table 1). The suppressive action on TNF $\alpha$ production at $10 \mu \mathrm{g} / \mathrm{mL}$ was best pronounced in the case of PUB4 and PUB6 (40-50\% inhibition). Nevertheless, due to its strongest antiproliferative

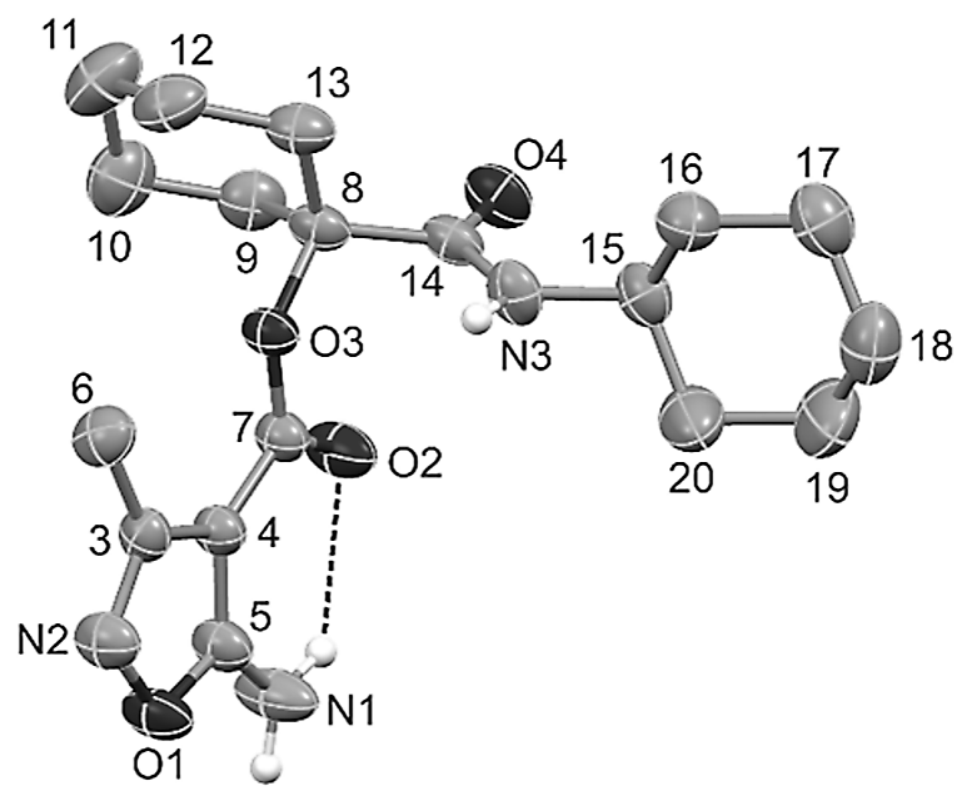

Figure 5. Molecular structure of PUB1 showing the atom-labelling scheme and intramolecular hydrogen bond (dashed line). The displacement ellipsoids are shown at the $50 \%$ of probability level. C-bound hydrogen atoms are omitted for clarity

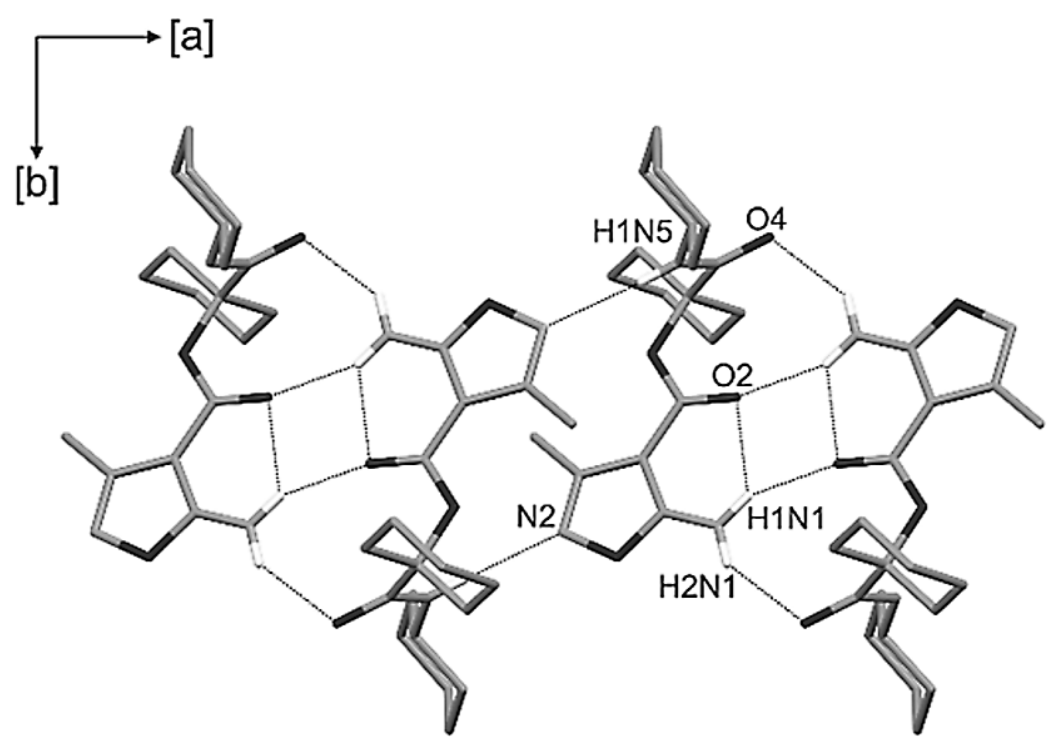

Figure 6. Hydrogen-bonded tapes in crystals of PUB1. Intramolecular and intermolecular hydrogen bonds are marked as dotted lines. Cbond hydrogen atoms are omitted for clarity 


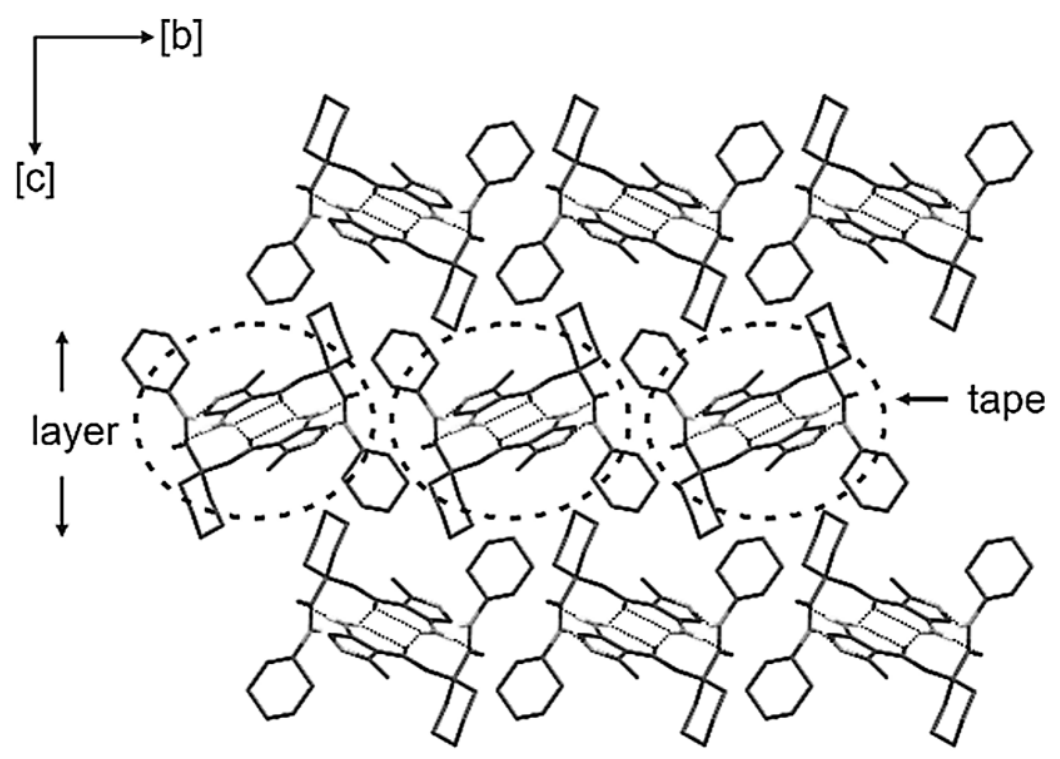

Figure 7. Crystal structure of PUB1 showing the layers perpendicular to the unit cell axis c consisting of hydrogen-bonded tapes (marked as dashed circles) extended along the a axis

action in the proliferation assay, PUB1 was selected for its potential activity in two-way human MLR model where it showed a statistically significant inhibitory action at $50 \mu \mathrm{g} / \mathrm{mL}$, but PUB4 was ineffective (Fig. 4). On the other hand, the compound did not inhibit the growth of L-1210 lymphoma and HT-29 colon tumor cells.

To find the molecular explanation for the antiproliferative action of PUB1 compound, we incubated the compound $(10 \mu \mathrm{g} / \mathrm{mL})$ with Jurkat cell for $24 \mathrm{~h}$. The appropriate dilution of DMSO (the solvent) represented the control culture. The results revealing changes in expression of signaling molecules potentially associated with apoptosis are depicted in Table 2. The results showed that the mechanism of action of PUB1 was probably associated with induction of cell apoptosis by a signaling pathway mediated by Fas and caspase 8 (26). No ability to induce expression of NF- $\mathrm{\kappa B} 1$ by the compound is in agreement with our results showing little effects of PUB1 on TNF $\alpha$ production (Table 1), and the data on association between expression of this transcription factor and TNF $\alpha$ production (27). The obtained results revealed that the activity of PUB8 is comparable to this presented by PUB1 in the PHA-induced PBMC proliferation. However, the compound did not inhibit MLR at $50 \mu \mathrm{g} / \mathrm{mL}$, displayed a poor solubility and was toxic with regard to A 549 cell line (not shown). PUB8 was also shown to inhibit the growth of T cell lymphoma L-1210 at
20-2.5 $\mu \mathrm{g} / \mathrm{mL}$ and HT-29 colon tumor at 20-5 $\mu \mathrm{g} / \mathrm{mL}$ concentration range. Interestingly, the compound induced in Jurkat cells downregulation of caspase $-3,-7$ and -8 and a strong (17x) increase of caspase- 9 expression. In addition, an appearance of p53, may contribute to the antiproliferative action of PUB8.

\section{X-ray structure}

The structure of PUB1 was determined by Xray crystallography (Fig. 5). The single crystal analysis revealed that PUB 1 crystallize in $\mathrm{P} 2 / \mathrm{n}$ space group with one molecule in the asymmetric unit. The exo-amine atom N1 has planar $\mathrm{sp}^{2}$ hybridization and its lone pair of electrons is conjugated with the $\mathrm{p}$ electron system of isoxazole ring which is reflected in shortening of the formally single N1-C5 bond (bond distance is $1.321 \AA$ ). The carboxylate fragment of the ester substituent at $\mathrm{C} 4$ is co-planar with the isoxazole ring whereas the (cyclohexylcarbamoyl)cyclohexyl moiety is practically perpendicular to the isoxazole ring (dihedral angles between isoxazole ring and the planes calculated through $\mathrm{C} 4, \mathrm{C} 7, \mathrm{O} 2$ and $\mathrm{O} 3$ atoms and atoms of (cyclohexylcarbamoyl)cyclohexyl fragment are $2.03(8)^{\circ}$ and $82.72(4)^{\circ}$, respectively). The ester carbonyl group is oriented toward the $\mathrm{C} 5$-amine group i.e. O2-C7-C4-C5 torsion angle is $1.6(2)^{\circ}$ that facilitates the formation of intramolecular $\mathrm{O} 2 \cdots \mathrm{H} 1 \mathrm{~N} 1-\mathrm{N} 1$ hydrogen bond 
(Table 3, Fig. 5). A similar type of an intramolecular hydrogen bond occurs also in seven available in the Cambridge Structural Data Base (28) structures of amide, azide and ester derivatives of 3methyl-4-isoxazolecarboxylic acid which are substituted at $\mathrm{C} 5$ by primary and secondary amine groups or imine group i.e. in compounds possessing proton-donor and proton-acceptor groups at $\mathrm{C} 4$ and $\mathrm{C} 5$ of the isoxazole ring. Conformational analysis of these structures shows that, as in PUB1, both groups involved in the intramolecular hydrogen-bonding are co-planar with the isoxazole ring. However, the carbonyl group at $\mathrm{C} 4$ adopts two different orientations relative to the isoxazole ring depending on the type of nitrogen atom (amine or imine) at C5. In structures with a proton-donor 5-amine group (29-32) the orientation of 4-carbonyl group is similar to that found in PUB1. In two structures of amide derivatives of 4isoxazolecarboxylic acid with proton-acceptor exo 4 imine $\mathrm{N}$ atom at C5 (33), the amide carbonyl group is rotated by approximately $180^{\circ}$ what enables the formation of intramolecular hydrogen bond between amine atom of 4-amide group and imine atom at $\mathrm{C} 5$.

Inspection of the crystal packing of PUB1 revealed that molecules related by symmetry centers associate via two types of intermolecular hydrogen bonds (N-H...O and $\mathrm{N}-\mathrm{H} . . . \mathrm{N})$ into tapes parallel to the unit cell axis $a$ (Fig. 6, Table 3). Translated along $\mathrm{b}$ axis tapes are arranged into (001) layers with cyclohexane rings situated on both sides of the layer (Fig. 7).

\section{CONCLUSIONS}

The proposed synthetic strategy allowed to synthesize a new class of isoxazole compounds, based on the 5-amino-3-methylisoxazole-4-carboxylic acid which may be rapidly synthesized and screened for biological activity. The obtained results showed that the main feature of the compounds was their ability to inhibit mitogen-induced lymphocyte proliferation. PUB1, the representative compound of the PUB series, analyzed for its mechanism of action in the model of Jurkat cells, was shown to induce Fas and elevate caspase 8 expression, a signaling pathway reported for proapoptotic action (26). On the other hand, caspases were not involved in the antiproliferative action of PUB1. The antiproliferative property of PUB1, associated with an apparent lack of cytotoxicity, may predispose the compound as a potential therapeutic for a variety of immunological disorders.

\section{Acknowledgment}

This research was financed by grant PBMN STM.D090.16.033 from Polish Ministry of Science and Higher Education for Wroclaw Medical University.

\section{REFERENCES}

1. Alsalameh S., Burian M., Mahr A.G., Woodcock B.G., Geisslinger G.: Aliment. Pharmacol. Ther. 17, 489 (2003).

2. Fox R.I., Herrmann M.L., Frangou C.G., Wahl G.M., Morris R.E. et al.: Clin. Immunol. 93, 198 (1999).

3. Brauner-Osborne H., Egebjerg J., Nielsen E.̌̌., Madsen U., Krogsgaard-Larsen P.: J. Med. Chem., 43, 2609 (2000).

4. Ryng S., Głowiak T.: Synth. Commun. 27, 1359 (1997).

5. Ryng S., Machoń Z., Wieczorek Z., Zimecki M.: Pharmazie 54, 359 (1999).

6. Ryng S., Zimecki M., Fedorowicz A., Jezierska A.: Arch. Pharm. 334, 71 (2001).

7. Jezierska A., Mączyński M., Koll A., Ryng S.: Arch. Pharm. 337, 81 (2004).

8. Ryng S., Machoń Z., Wieczorek Z., Zimecki M., Mokrosz M.: Eur. J. Med. Chem. 33, 831 (1998).

9. Ryng S., Zimecki M., Fedorowicz A., Koll A.: Pol. J. Pharmacol. 51, 257 (1999).

10. Ryng S., Machoń Z., Wieczorek Z., Zimecki M.: Pharmazie 54, 359 (1999).

11. Ryng S., Zimecki M., Sonnenberg Z., Mokrosz M.J.: Arch. Pharm. 332, 158 (1999).

12. Ryng S., Zimecki M., Fedorowicz A., Jezierska A., Głowiak T.: Acta Pol. Pharm. 60, 225 (2003).

13. Mączyński M., Zimecki M., Ryng S.: Acta Pol. Pharm. Drug Res. 65, 241 (2008).

14. Mączyński M., Artym J., Kocięba M., Sochacka-Ćwikła A., Drozd-Szczygieł E. et al.: Acta Pol. Pharm. 73, 1201 (2016).

15. Mączyński M., Ryng S., Artym J., Kocięba M., Zimecki M. et al.: Acta Pol. Pharm. Drug Res. 71, 71 (2014).

16. Dömling A., Wang W., Wang K.: Chem. Rev. 112, 3083 (2012).

17. Wang K., Dömling A.: Chem. Biol. Drug Des. 75, 277 (2010).

18. Passerini M.: Gazz. Chim. Ital. 51, 126 (1921).

19. Hansen M.B., Nielsen S.E., Berg K.: J. Immunol. Methods 119, 203 (1989).

20. Rigaku Oxford Diffraction. CrysAlis PRO. Rigaku Oxford Diffraction, Yarnton, England (2015). 
21. Sheldrick G.M.: Acta Crystallogr. A71, 3 (2015).

22. Sheldrick G.M.: Acta Crystallogr. C71, 3 (2015).

23. Mączyński M., Artym J., Kocięba M., Kochanowska I., Ryng S., Zimecki M.: Pharmacol. Rep. 68, 894 (2016).

24. Klötzer W.: Monatsh. Chem. 255 (1964).

25. Machoń Z., Ryng S.: Arch. Immunol. Ther. Exp. 29, 813 (1981).

26. Juo P., Kuo C.J., Yuan J., Blenis J.: Curr. Biol. 8,1001 (1998)

27. Deshpande R., Khalili H., Pergolizzi R.G., Michael S.D., Chang M.D.: Am. J. Reprod. Immunol. 38, 46 (1997).
28. Groom C.R., Bruno I.J., Lightfoot M.P., Ward S.C.: Acta Crystallogr. B Struct. Sci. Cryst. Eng. Mater. B72, 171 (2016).

29. Jezierska A., Zygmunt J., Głowiak T., Koll A., Ryng S.: Pol. J. Chem. 77, 1461 (2003).

30. Sony S.M.M., Charles P., Ponnuswamy M.N., Yathirajan H.S., Nethaji M.: Acta Crystallogr. Sect. E: Struct. Rep. Online 61, o198 (2005).

31. Ryng S., Machoń Z., Głowiak T.: J. Chem. Cryst. 24, 483 (1994).

32. Schmitt E., Bouvet S., Pegot B., Panossian A., Vors J.P. et al.: Org. Lett. 19, 4960 (2017).

33. Ryng S., Głowiak T.: J. Chem. Cryst. 28, 373 (1998).

Received: 31.07 .2018 